\title{
Short communication: Does previous superovulation affect fertility in dairy heifers?
}

\author{
C. A. C. Fernandes, ${ }^{1,2 *} \odot$ G. H. S. Pereira, ${ }^{1} \oplus$ L. G. B. Siqueira, ${ }^{3} \oplus$ H. L. D. H. Neri, ${ }^{2} \odot$ J. H. M. Viana, ${ }^{4} \odot$ \\ M. P. Palhao, ${ }^{1}$ (i) and R. A. S. Teodoro ${ }^{1}$ (i) \\ ${ }^{1}$ Universidade José do Rosário Vellano, Alfenas, MG, Brazil 37130-000 \\ ${ }^{2}$ Biotran Biotecnologia, Alfenas, MG, Brazil 37130-000 \\ ${ }^{3}$ Embrapa Gado de Leite, Juiz de Fora, MG, Brazil 36038-330 \\ ${ }^{4}$ Embrapa Recursos Genéticos e Biotecnologia, Brasília, DF, Brazil 70770-917
}

\section{ABSTRACT}

The aim of this study was to evaluate the potential negative effects of superovulation on subsequent fertility of dairy heifers. Holstein heifers $(\mathrm{n}=1,783), 312$ to 387 $\mathrm{d}$ of age, and 273 to $307 \mathrm{~kg}$ of body weight (BW) from 2 commercial farms were enrolled. These animals were first selected to be donors (446) or nondonors (CON, n $=1,327)$ according to their genomic values. Nondonor heifers (CON) were artificially inseminated (AI) according to standard procedures of each farm after reaching $320 \mathrm{~kg}$ of BW. Donor heifers were superovulated using a fixed FSH dose (180 mg NIH-FSH-P1; Folltropin-V, Vetoquinol Brasil, Mairiporã, SP, Brazil) and embryos were collected following standard procedures. Heifers that produced fewer than 8 viable embryos after first superovulation ( $\mathrm{SOV} 1, \mathrm{n}=337$ ) were no longer used as donors, whereas the remaining heifers (SOV2, $\mathrm{n}=109$ ) were superovulated a second time within an interval of 48 to $54 \mathrm{~d}$. Donor heifers (SOV1 and SOV2) were AI once they reached $320 \mathrm{~kg}$ of $\mathrm{BW}$, at least $15 \mathrm{~d}$ after the last embryo collection. Data on age at first AI, at conception, and at parturition, as well as the number of services per conception, were analyzed by ANOVA, using the PROC MIXED procedure of SAS (SAS Institute Inc., Cary, NC) procedure. Binomial variables (pregnancy per AI, overall pregnancy rate, open heifers at $500 \mathrm{~d}$ age, and late pregnancy loss) were analyzed using the GLIMMIX procedure of SAS. The heifers selected to undergo superovulation twice (SOV2) yielded more total (12.6 \pm 5.3 vs. $6.8 \pm 4.6$; respectively) and viable embryos ( $8.5 \pm 3.8$ vs. $3.9 \pm 2.8$; respectively) than those superovulated only once (SOV1). Age at first AI, conception, and at parturition was greater in SOV2, but not in SOV1 compared with nondonor controls. In addition, pregnancy per first AI, overall pregnancy

Received February 18, 2020

Accepted June 29, 2020.

*Corresponding author: carlos@biotran.com.br rate, services per conception, open heifers at $500 \mathrm{~d}$ of age, and occurrence of pregnancy losses after $60 \mathrm{~d}$ of gestation were similar among CON, SOV1, and SOV2 heifers. In summary, a single superovulation performed before heifers reach a minimum weight for breeding did not affect age at conception, calving or other indicators of reproductive efficiency. On the other hand, heifers superovulated twice were first inseminated at a later age than their birth cohorts, but had similar reproductive performance.

Key words: bovine, biotechnology, reproductive efficiency

\section{Short Communication}

Multiple ovulation and embryo transfer protocols have long been a very important tool for cattle breeding programs (Hasler, 2003). Ovulation of multiple follicles can be induced in mono-ovulatory species such as cattle by the exogenous treatment with FSH (Moore and Hasler, 2017). After such superstimulatory treatments, numerous follicles may reach later stages of development, ovulate, and form multiple corpora lutea, eventually leading to the development of several embryos. As a result, supraphysiological serum concentrations of ovarian-borne steroids (estradiol and progesterone) and a massive increase in ovary size occur, leading to an amount of luteal tissue as large as 25 -fold greater than the observed after a single ovulation (Viana et al., 2016). The abnormal steroid concentrations may disturb tubal and uterine microenvironment and are a risk factor for the development of cystic ovarian disease (Todoroki et al., 2004), which may compromise subsequent fertility.

Until the early 2000s, several studies evaluated the potential negative effects of superovulatory treatments on reproductive success. Results were, however, controversial and suggested either a negative effect (Cowen and Sosnik, 1987; Bak et al., 1989) or no effect (Hackett and McAllister, 1992; Lopes da Costa et al., 
2001; Smith, 2001) on reproductive performance. Nevertheless, this research question progressively received less attention in the past years, as the main focus was concentrated on embryo yield per superovulation and, more recently, the development of in vitro technologies (Moore and Hasler, 2017). The concern about the effect of superstimulation on future reproduction, however, is reemerging. There is an increase in the use of FSH for preparation of oocyte donors for in vitro embryo production (Matoba et al., 2014) and, due to the advances in genomics, there is a clear trend favoring the use of heifers as donors instead of adult cows (Mikkola et al., 2020). These young females are likely to remain in the herds for longer periods than adult cows, so long-term reproductive efficiency is critical.

In the past 40 years, there was a substantial improvement in the purity and quality of commercially available FSH preparations as well as the development of new superovulation (SOV) protocols (Bó and Mapletoft, 2014). Concurrently, an increase in the knowledge of ovarian physiology, particularly on follicular dynamics and luteal function, led to improved strategies for the management of embryo donors subjected to superovulation regimens. Thus, the aim of this study was to evaluate the potential effect of superovulation on subsequent fertility of dairy heifers in light of the current state-of-the-art procedures adopted in this technique.

This study was performed in 2 dairy farms at the state of Minas Gerais, Brazil, located at an altitude of 750 to $880 \mathrm{~m}$ and with CW (dry-winter subtropical) climate, according to Köppen (Alvares et al., 2013). The study was previously approved (protocol \#28A/17) by the Ethics in Animal Use Committee of the University José do Rosário Vellano. A total of 1,783 Holstein heifers, 312 to $387 \mathrm{~d}$ of age and 273 to $307 \mathrm{~kg}$ of BW, were enrolled in the experiment. Heifers were weighed monthly. First, females were selected to be embryo donors (446) or nondonors ( $\mathrm{CON} ; \mathrm{n}=1,327$ ), based on genomic values for production and economical traits, previously determined using a microchip containing selection markers (Clarifide, Zoetis, São Paulo, SP, Brazil). Genomic testing was performed between 60 and $120 \mathrm{~d}$ of age and the criteria used for donor selection were based on genetic merit defined by each farm, according to their own goals.

Nondonor heifers (CON) were artificially inseminated following the standard operational procedures of reproductive management on each farm, after reaching a minimum BW of $320 \mathrm{~kg}$. Briefly, heifers bearing a corpus luteum (CL) detected by monthly ovarian ultrasonography received a $\mathrm{PGF}_{2 \alpha}$ injection (Estron, Agener) followed by estrus detection. Those detected in estrus within 2 to $10 \mathrm{~d}$ were inseminated, whereas those not detected in estrus received a second $\mathrm{PGF}_{2 \alpha}$ injection $11 \mathrm{~d}$ after the first. Heifers without a CL in 2 subsequent ultrasound exams and those not observed in estrus after the second $\mathrm{PGF}_{2 \alpha}$ were submitted to a timed AI (TAI) protocol. Pregnancy diagnosis was performed $28 \mathrm{~d}$ after AI or TAI by B-mode ultrasonography and confirmed $30 \mathrm{~d}$ later.

As for heifers selected to be embryo donors, those were treated with a protocol for synchronization of follicular wave emergence and SOV using a standard FSH dose for all females (180 mg NIH-FSH-P1, Folltropin-V, Vetoquinol Brasil, Mairiporã, SP, Brazil) and a conventional 4-d superovulatory treatment, with 8 i.m. injections of decreasing FSH doses, as described in Table 1. Embryo collection was performed $7 \mathrm{~d}$ after timed AI. Briefly, each uterine horn was individually flushed at least 6 times, using 500 to $700 \mathrm{~mL}$ of Dulbecco's modified phosphate-buffered saline (DMPBS, Reprodux, Campinas, SP, Brazil). Harvested embryos were identified, placed into a holding medium (ViGRO Holding Plus, Vetoquinol, Fort Worth, TX) and then graded for quality according to the criteria proposed by Lindner and Wright (1983). Heifers that produced fewer than 8 viable embryos in this first SOV procedure were no longer used as donors (SOV1, $\mathrm{n}=337$ ), whereas the remaining heifers (SOV2, $\mathrm{n}=109$ ) underwent a second SOV within an interval of 48 to $54 \mathrm{~d}$ after embryo collection.

Immediately after embryo collection, all heifers received $0.5 \mathrm{mg}$ sodium cloprostenol i.m. ( $\mathrm{PGF}_{2 \alpha}$; Estron, Agener, São Paulo, SP, País) and 7 to 10 d later were evaluated using B-mode ultrasonography (Mindray M5, Mindray do Brasil, Monções, SP, Brazil), taking into account the expected delay in luteal regression in superstimulated heifers with multiple corpora lutea previously reported in cattle (Viana et al., 2016). Heifers with no abnormalities detected in the genital tract at the ultrasound exam (all but one heifer in SOV1 and 2 heifers in SOV2) and $\geq 320 \mathrm{~kg} \mathrm{BW}$ were considered eligible for AI following the routine reproductive management of each farm, as described for the nondonor heifers.

Data on age at first AI, conception, parturition, and number of services per conception were examined for normality and then analyzed by ANOVA, using the SAS MIXED procedure. The statistical model included the main effect of group (CON, SOV1, SOV2) and farm as a random effect. If a significant effect was detected, differences among means were determined using the Tukey's post hoc test. Binomial endpoints (pregnancy per AI, overall pregnancy rate, open heifers at $500 \mathrm{~d}$ of age, and proportion of late embryonic loss) were analyzed using the SAS GLIMMIX procedure. All analyses were performed using the SAS software (Statistical Analysis System, Version 9.3 for Windows; SAS Insti- 
Table 1. Superovulatory protocol used in embryo donor Holstein heifers ${ }^{1}$

\begin{tabular}{|c|c|c|}
\hline \multirow{2}{*}{$\begin{array}{l}\text { Day of } \\
\text { protocol }\end{array}$} & \multicolumn{2}{|c|}{ Time } \\
\hline & $0700 \mathrm{~h}$ & $1900 \mathrm{~h}$ \\
\hline 0 & $\mathrm{P} 4$ intravaginal device $+2 \mathrm{mg} \mathrm{EB}$ i.m. & \\
\hline 4 & $36 \mathrm{mg}$ of FSH i.m. & $36 \mathrm{mg}$ of FSH i.m. \\
\hline 5 & $27 \mathrm{mg}$ of FSH i.m. & $27 \mathrm{mg}$ of FSH i.m. \\
\hline 6 & 18 mg of FSH i.m. & 18 mg of FSH i.m. \\
\hline 7 & $9 \mathrm{mg}$ of FSH i.m. $+0.5 \mathrm{mg}$ of $\mathrm{PGF}_{2 \alpha}$ analog & $9 \mathrm{mg}$ of FSH i.m. and $\mathrm{P} 4$ device withdrawal \\
\hline 8 & & $0.1 \mathrm{mg}$ of GnRH i.m. \\
\hline 9 & First TAI & Second TAI \\
\hline
\end{tabular}

tute, Cary, NC). Results are presented as mean \pm SEM and a $P$-value of 0.05 was used to determine statistical significance.

We did not detect a farm effect on any of the outcome variables analyzed, so data from both farms were combined to increase statistical power. As expected, due to the experimental design, heifers selected to undergo SOV twice (SOV2) yielded a greater number of total and viable embryos $(P<0.01)$ compared with those superovulated only once (SOV1). Similarly, age at first AI, conception, and parturition was greater $(P<0.05)$ in SOV2 compared with nondonor controls (CON). Nevertheless, heifers submitted to a single SOV (SOV1) were not affected $(P>0.05)$ on any of these endpoints, compared with CON. Reproductive performance, however, did not differ among the 3 groups. Pregnancy per AI (P/AI) at first AI, overall pregnancy rate, number of services per conception, percentage of open heifers at $500 \mathrm{~d}$ of age, and proportion of pregnancy loss after 60 $\mathrm{d}$ of gestation were similar $(P>0.05)$ in CON, SOV1, and SOV2 (Table 2).
The increase in age at first AI, conception, and parturition observed in our experiment in females submitted to SOV twice reflected a management decision rather than a direct detrimental effect of superovulation on subsequent fertility. It is noteworthy that we observed an increase of approximately $30 \mathrm{~d}$ on these endpoints in SOV2 compared with CON, half the time in days required to perform the second SOV in SOV2 heifers ( 48 to $54 \mathrm{~d}$ interval from last embryo collection plus a 16-d SOV protocol). In SOV1, because SOV was performed before heifers achieved the minimum weight for breeding, we did not observe a significant delay in reproductive performance. Is this matter, it is likely that differences in reproductive management of donors may have contributed to the controversial debate about the potential negative effects of SOV on reproductive performance reported by previous studies in cattle. For instance, the study of Cowen and Sosnik (1987) observed an increase in days open in lactating Holstein cows submitted to SOV, but not proportional to the increase in the number of services per conception. Actually, in this

Table 2. Outcome variables analyzed in Holstein heifers undergoing AI as they reached $320 \mathrm{~kg}$ of BW (CON) or used as embryo donors after superovulation before entering AI routine ${ }^{1}$

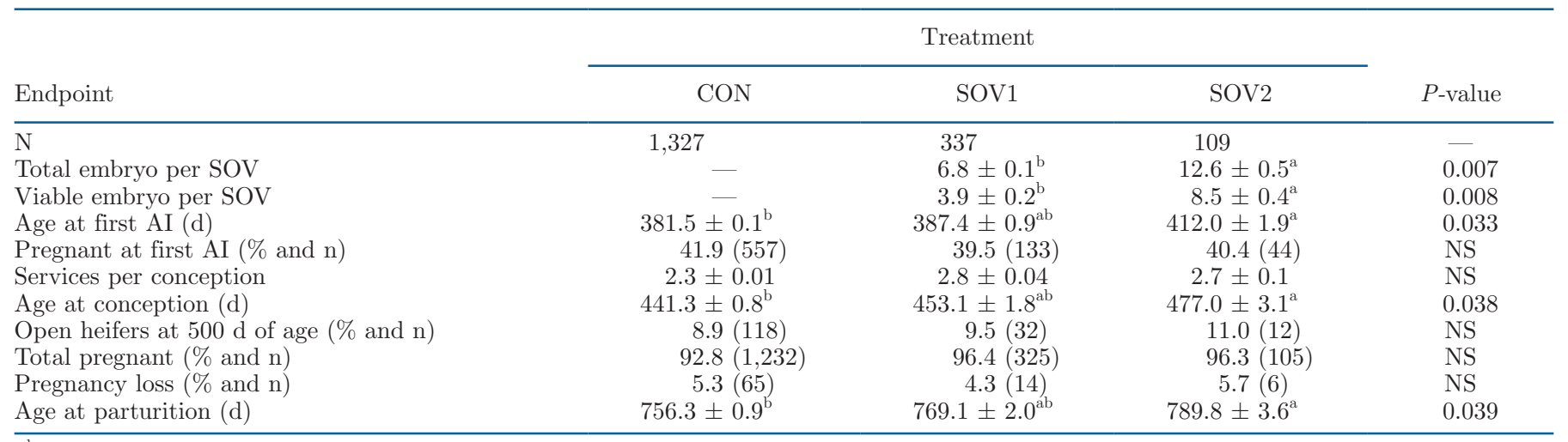

${ }^{\mathrm{a}, \mathrm{b}}$ Within a row, means with different superscripts differ $(P<0.05)$.

${ }^{1} \mathrm{CON}=$ control; SOV $1=$ heifers superovulated once; SOV2 $=$ heifers superovulated twice. 
study the main component for the increase in days open was the number of days before first service. Similarly, Oshima et al. (2012) reported that donor management, rather than the SOV protocol per se, affected fertility after embryo collection of Japanese black cows. In the current study, the lack of difference in pregnancy and late embryonic loss rates among groups suggests that reproductive health was fully reestablished after either one (SOV1) or 2 (SOV2) embryo collection events.

A potential bias in retrospective studies in dairy herds that use embryo technologies is the expected difference between milk yield of females selected as donors compared with their herdmates (Siqueira et al., 2020), with possible consequent differences in management, nutrition, metabolic status, and reproductive performance of high-producing animals (Sartori et al., 2010). If this effect is not controlled, as in many retrospective studies (Cowen and Sosnik, 1987; Smith, 2001), the association between SOV and subsequent conception rates remains unclear. In our study, we enrolled only heifers with similar age and weight, thus avoiding such confounding factors. Indeed, no differences in reproductive performance were observed among groups.

On the other hand, most cows and heifers are selected as embryo donors based on a higher genetic merit, which is usually calculated taking in account multiple traits, including fertility. Although fertility represents only a fraction of the weight of selection indexes, this could be a potential bias in studies comparing groups of donor and nondonor cows. In our study, heifers from SOV1 and SOV2 were previously selected based on genomic values. However, differences were only observed for endpoints directly affected by the management decision of postponing or not AI (age at first AI, at conception, or at parturition), whereas those potentially influenced by genetic merit were similar among groups.

The CL progressively increases responsiveness to $\mathrm{PGF}_{2 \alpha}$ treatment during early diestrus and, therefore, incomplete luteolysis may occur after $\mathrm{PGF}_{2 \alpha}$ treatment of donors soon after embryo collection (Mapletoft et al., 1991; Viana et al., 2016). The resulting rebound in progesterone production may contribute to a delay in return to estrus and thus increase the number of days open, particularly when donors are not examined frequently after embryo collection. In this regard, incomplete or failed luteolysis may account for part of the alleged side effects of SOV (delayed return to estrus, cystic ovarian disease, and infertility). Therefore, ensuring complete luteolysis after SOV is essential to reduce the interval between SOV or interval to AI following embryo collection (Bó and Mapletoft, 2014).

Our experimental design selected only heifers yielding more than 8 viable embryos at the first SOV to undergo a second SOV protocol. Our results highlight the effect of donor selection on the average embryo production per SOV, which was 2-fold greater in SOV2 than in SOV1. By using this strategy, only approximately $25 \%$ of the potential donors (determined by genomic testing) will experience a significant delay in age at conception and parturition.

In summary, a single superovulation performed before heifers reach a minimum weight for breeding did not affect age at conception, calving, or other indicators of reproductive efficiency. On the other hand, heifers superovulated twice were first inseminated at a later age than their birth cohorts but had similar reproductive performance.

\section{ACKNOWLEDGMENTS}

The authors thank Biotran Ltd. (Alfenas, MG, Brazil) for the support during data collection. This research was supported by grants from Fundação de Amparo a Pesquisa do Estado de Minas Gerais (FAPEMIG) and Conselho Nacional de Desenvolvimento Científico e Tecnológico $(\mathrm{CNPq})$. The authors have not stated any conflicts of interest.

\section{REFERENCES}

Alvares, C. A., J. L. Stape, P. C. Sentelhas, J. L. de Moraes Gonçalves, and G. Sparovek. 2013. Köppen's climate classification map for Brazil. Meteorol. Z. (Berl.) 22:711-728. https://doi.org/10.1127/ 0941-2948/2013/0507.

Bak, A., T. Greve, and M. Schmidt. 1989. Effect of superovulation on reproduction. Theriogenology 31:169. https://doi.org/10.1016/ 0093-691X(89)90577-3.

Bó, G. A., and R. J. Mapletoft. 2014. Historical perspectives and recent research on superovulation in cattle. Theriogenology 81:3848. https://doi.org/10.1016/j.theriogenology.2013.09.020.

Cowen, P., and U. Sosnik. 1987. Effect of superovulation on lactating holsteins. Theriogenology 28:783-788. https://doi.org/10.1016/ 0093-691X(87)90030-6.

Hackett, A. J., and A. J. McAllister. 1992. Effect of two superovulation treatments on subsequent fertility in the confined dairy cow. Theriogenology 38:833-841. https://doi.org/10.1016/0093 -691X(92)90159-O.

Hasler, J. F. 2003. The current status and future of commercial embryo transfer in cattle. Anim. Reprod. Sci. 79:245-264. https://doi .org/10.1016/S0378-4320(03)00167-2.

Lindner, G. M., and R. W. Wright Jr.. 1983. Bovine embryo morphology and evaluation. Theriogenology 20:407-416. https://doi.org/ 10.1016/0093-691X(83)90201-7.

Lopes da Costa, L., J. Chagas e Silva, and J. Robalo Silva. 2001. Superovulatory response, embryo quality and fertility after treatment with different gonadotrophins in native cattle. Theriogenology 56:65-77. https://doi.org/10.1016/S0093-691X(01)00543-X.

Mapletoft, R., G. Bo, N. Willmott, and R. Pierson. 1991. The effect of dose of cloprostenol on return to estrus of superovulated donor cows. Theriogenology 35:237-245. https://doi.org/10.1016/0093 $-691 X(91) 90213-W$.

Matoba, S., H. Yoshioka, H. Matsuda, S. Sugimura, Y. Aikawa, M. Ohtake, Y. Hashiyada, T. Seta, K. Nakagawa, P. Lonergan, and K. Imai. 2014. Optimizing production of in vivo-matured oocytes from superstimulated Holstein cows for in vitro production of embryos using X-sorted sperm. J. Dairy Sci. 97:743-753. https://doi .org/10.3168/jds.2013-6838. 
Mikkola, M., J. F. Hasler, and J. Taponen. 2020. Factors affecting embryo production in superovulated Bos taurus cattle. Reprod. Fertil. Dev. 32:104-124. https://doi.org/10.1071/RD19279.

Moore, S. G., and J. F. Hasler. 2017. A 100-year review: Reproductive technologies in dairy science. J. Dairy Sci. 100:10314-10331. https: //doi.org/10.3168/jds.2017-13138.

Oshima, K., Y. Ochiai, T. Kojima, and N. Yamamoto. 2012. Effect of restricted suckling on the superovulatory response and reproductive performance in postpartum Japanese black cows. J. Vet. Med. Sci. 74:1469-1475. https://doi.org/10.1292/jvms.12-0026.

Sartori, R., M. R. Bastos, and M. C. Wiltbank. 2010. Factors affecting fertilisation and early embryo quality in single- and superovulated dairy cattle. Reprod. Fertil. Dev. 22:151-158. https://doi.org/10 .1071/RD09221.

Siqueira, L. G., M. V. G. Silva, J. C. Panetto, and J. H. Viana. 2020. Consequences of assisted reproductive technologies for offspring function in cattle. Reprod. Fertil. Dev. 32:82-97. https://doi.org/ 10.1071/RD19278.

Smith, A. K. 2001. Retrospective study of the effect of superovulation on subsequent fertility in embryo-transfer donors. Vet. Rec. 148:114-116. https://doi.org/10.1136/vr.148.4.114.

Todoroki, J., J. Noguchi, K. Kikuchi, and H. Kaneko. 2004. Retrospective analysis of the efficacy of controlled internal drug release in follicular cysts in an embryo donor beef herd. J. Reprod. Dev. 50:369-373. https://doi.org/10.1262/jrd.50.369.

Viana, J. H. M., M. S. B. Vargas, L. G. B. Siqueira, L. S. A. Camargo, A. C. S. Figueiredo, C. A. C. Fernandes, and M. P. Palhao. 2016. Efficacy of induction of luteolysis in superovulated cows is dependent on time of prostaglandin F2alpha analog treatment: Effects on plasma progesterone and luteinizing hormone profiles. Theriogenology 86:934-939. https://doi.org/10.1016/j.theriogenology .2016.03.016.

\section{ORCIDS}

C. A. C. Fernandes (ํ) https://orcid.org/0000-0003-1764-7866

G. H. S. Pereira (ㄴ) https://orcid.org/0000-0001-7247-9012

L. G. B. Siqueira (ㄴ) https://orcid.org/0000-0002-2800-5829

H. L. D. H. Neri ৫ib https://orcid.org/0000-0001-5964-8686

J. H. M. Viana (1) https://orcid.org/0000-0002-3742-2368

M. P. Palhao ( https://orcid.org/0000-0002-6670-4946

R. A. S. Teodoro (1) https://orcid.org/0000-0003-1312-7820 